\title{
Cuidados durante o tratamento endodôntico no paciente oncológico
}

\author{
Care during endodontic treatment in cancer patients \\ Cuidados durante el tratamiento endodóntico en paciente oncológico
}

Recebido: 24/08/2021 | Revisado: 29/08/2021 | Aceito: 03/09/2021 | Publicado: 06/09/2021

\author{
Fernanda Ladico Miura \\ ORCID: https://orcid.org/0000-0002-4250-021X \\ Universidade Federal de Uberlândia, Brasil \\ E-mail: fernandaladico@gmail.com \\ Eduardo Melo Franco Santiago Cardoso \\ ORCID: https://orcid.org/0000-0001-9526-3003 \\ Faculdade Patos de Minas, Brasil \\ E-mail: eduardo.mfsc@gmail.com \\ Cizelene do Carmo Faleiros Veloso Guedes \\ ORCID: https://orcid.org/0000-0001-7128-7537 \\ Faculdade Patos de Minas, Brasil \\ E-mail: cizelene@hotmail.com
}

\begin{abstract}
Resumo
O objetivo do presente trabalho foi apresentar os principais desafios e cuidados durante o tratamento odontológico no paciente oncológico, com ênfase aos cuidados durante a realização do tratamento endodôntico. Metodologia: Relato de três casos clínicos de pacientes que apresentaram necessidade de tratamento endodôntico e encontravam-se em tratamento oncológico. Resultados: A maioria dos pacientes oncológicos apresentam necessidades odontológicas importantes e precisam de cuidados minuciosos antes, durante e após a oncoterapia. A principal finalidade do tratamento odontológico nestes pacientes é estabilizar as condições bucais para reduzir ou eliminar o risco de infecção local e sistêmica, como também acompanhar o possível surgimento de sequelas resultantes do tratamento oncológico. Conclusão: $\mathrm{O}$ tratamento endodôntico tem por finalidade minimizar o risco de complicações e melhorar a qualidade de vida do paciente. $\mathrm{E}$ a interação do cirurgião-dentista com a equipe oncológica na atenção e cuidado do paciente em tratamento é extremamente importante em todos os estágios da doença.
\end{abstract}

Palavras-chave: Oncologia; Endodontia; Radioterapia; Bisfosfonatos; Transplante de medula óssea.

\begin{abstract}
The objective of the present work was to present the main challenges and cares during the dental treatment of cancer patients, with emphasis on the care during the endodontic treatment. Methodology: Report of three clinical cases of patients who needed endodontic treatment and were undergoing cancer treatment. Results: Most cancer patients have important dental needs and need detailed care before, during and after cancer therapy. The main purpose of dental treatment in these patients is to stabilize oral conditions to reduce or eliminate the risk of local and systemic infection, as well as to monitor the possible emergence of sequelae resulting from cancer treatment. Conclusion: Endodontic treatment aims to minimize the risk of complications and improve the patient's quality of life. And the interaction of the dentist with the oncology team in the care and care of the patient undergoing treatment is extremely important in all stages of the disease.
\end{abstract}

Keywords: Oncology; Endodontics; Radiotherapy; Bisphosphonates; Bone marrow transplantion.

\section{Resumen}

El objetivo del presente trabajo fue presentar los principales desafíos y cuidados durante el tratamiento odontológico de los pacientes con cáncer, con énfasis en los cuidados durante el tratamiento endodóntico. Metodología: Informe de tres casos clínicos de pacientes que necesitaron tratamiento endodóntico y estaban en tratamiento oncológico. Resultados: la mayoría de los pacientes con cáncer tienen necesidades dentales importantes y necesitan cuidados detallados antes, durante y después de la terapia contra el cáncer. El principal objetivo del tratamiento odontológico en estos pacientes es estabilizar las condiciones bucales para reducir o eliminar el riesgo de infección local y sistémica, así como vigilar la posible aparición de secuelas derivadas del tratamiento oncológico. Conclusión: El tratamiento de endodoncia tiene como objetivo minimizar el riesgo de complicaciones y mejorar la calidad de vida del paciente. Y la interacción del odontólogo con el equipo de oncología en el cuidado y cuidado del paciente en tratamiento es de suma importancia en todas las etapas de la enfermedad.

Palabras clave: Oncología; Endodoncia; Radioterapia; Bisfosfonatos; Trasplante de médula óssea. 


\section{Introdução}

$\mathrm{Na}$ atualidade o número de casos de câncer aumentou de maneira considerável em todo o mundo e tem sido um dos problemas mais importantes de saúde pública (Guerra, Gallo, \& Mendonça, 2005). O câncer é definido como uma doença crônica, que pode causar dor física, sofrimento emocional e espiritual significativos. Em fases avançadas, a chance de sobrevida do paciente diminui. Segundo o Instituto Nacional do Câncer (INCA), no Brasil é a segunda causa de morte (Santos, Lattaro, \& Almeida, 2011). O câncer ocorre quando mutações nos genes de uma única célula tornam a mesma capaz de se proliferar rapidamente e tornar-se uma massa tumoral e para que esta adquira caráter de um tumor maligno várias transformações devem ocorrer na mesma célula (Yamaguchi, 2002).

Dentre as modalidades de tratamento do câncer podemos citar a cirurgia, a radioterapia e a quimioterapia ou associação de ambas (Sena Souza Morais Pinto \& Melo 2001). Porém a terapia antineoplásica pode acarretar aos pacientes oncológicos algumas complicações orais imediatas ou tardias. Este fato ocorre porque o tratamento oncológico é capaz de destruir células tumorais, mas também lesionar células saudáveis. Dentre as complicações mais comuns na cavidade oral encontram-se a mucosite, xerostomia, disgeusia, infecções fúngicas, bacterianas e virais, cáries relacionadas à radiação, trismo, osteorradionecrose, neurotoxicidade (Paiva, Biase, Moraes, Ângelo, \& Honorato, 2016) e a osteonecrose dos maxilares associada ao uso de bisfosfonatos (Barin, Pillusky, Pasini, \& Danesi, 2010).

O tratamento radioterápico destrói grande quantidade de células neoplásicas, porém as células sadias adjacentes também são afetadas (Pinto, Maia, \& Brito 2001), e também reduz a capacidade proliferativa da célula (Sena Souza Morais Pinto \& Melo 2001). A utilização da radioterapia é considerada um tratamento loco-regional contra o câncer na região de cabeça e pescoço, porém, pode causar alterações visíveis nos tecidos adjacentes às áreas irradiadas, dessa forma são necessários alguns cuidados prévios ao tratamento para prevenir ou amenizar os efeitos decorrentes da radioterapia (de Castro, Dezotti, L., Aquilante, \& Xavier, 2002).

A osteorradionecrose é a complicação tardia mais grave da radioterapia na região de cabeça e pescoço. É caracterizada por edema e eritema em tecidos moles, exposição de osso necrótico, trismo, ulceração, linfadenopatia localizada ou generalizada, supuração intra ou extra-oral, dor, parestesia e fratura patológica (Katanas, Rogers, \& Martin, 2002). A causa principal para o seu desenvolvimento é a deterioração da circulação óssea e dos tecidos circunjacentes e a redução de osteócitos e osteoblastos (Jereczek-Fossa, \& Orecchia, 2002). Essa complicação tem um curso demorado e sofrido, afetando diretamente a qualidade de vida do paciente oncológico (Paiva, Biase, Moraes, Ângelo, \& Honorato, 2016).

Nos pacientes oncológicos que apresentam hipercalcemia maligna moderada a grave, assim como metástases ósseas associadas a qualquer tumor sólido ou mieloma múltiplo, a administração intravenosa de bisfosfonatos (ibandronato, pamidronato, zolendronato) é indicada como tratamento. São utilizados também para o tratamento de osteoporose, para o tratamento da doença de Paget (menos comum) e para a osteogênese imperfeita na infância. Nestes casos a indicação do uso de bisfosfonatos é por via oral (etidronato, tiludronato, alendronato, risendronato, ibandronato) (Bartl et al, 2007). Os bisfosfonatos são considerados análogos sintéticos e estáveis do pirofosfato e são capazes de ligarem-se seletivamente as zonas ativas de reabsorção óssea e diminuírem a atividade osteoclástica (Coelho, Gomes, \& Fernandes, 2010).

Uma das mais importantes complicações orais observadas advindas da terapia com bisfosfonatos é a osteonecrose dos maxilares (OMAB). A OMAB é caracterizada por uma região de osso exposto necrótico, na área maxilofacial, que não cicatriza, identificada em pacientes que fizeram ou estão em uso de bisfosfonatos e não tem história clínica de radioterapia na região (Ruggiero, Mehrotra, Rosenberg, \& Engroff, 2004; Ruggiero 2009)

O transplante de medula óssea (TMO) atualmente é o tratamento de escolha para diversas doenças que interferem na produção de células mãe hematopoiéticas e de elementos do sistema imunológico. Afim de evitar a rejeição do transplante pelo sistema imune do paciente, há a necessidade da adoção de algumas medidas complementares como a quimioterapia e/ou 
radioterapia, que tem por finalidade causar grave depressão do sistema imunológico e, por consequência, causam manifestações paralelas nem sempre desejáveis, sendo o sistema estomatognático um local afetado com frequência (Santos, \& Magalhães, 2006; Lima, 2010).

As infecções bacterianas bucais em pacientes mielossuprimidos (condição em que a atividade da medula óssea é diminuída, resultando em menor número de glóbulos vermelhos, glóbulos brancos e plaquetas), são comumente associadas à doença periodontal e endodôntica, nestes indivíduos imunodeprimidos, microrganismos considerados de baixa virulência podem tornar-se capazes de desencadearem infecções locais ou sistêmicas importantes (Silverman et al, 2002).

Em pacientes submetidos à quimioterapia, antes de realizar intervenções odontológicas, deve-se atuar juntamente com o médico responsável, considerando que, há possibilidade de infecções decorrentes da mielossupressão e imunossupressão, e além disso, a quimioterapia pode aumentar o risco de hemorragia durante o procedimento odontológico, devido principalmente a redução do número de plaquetas (Silva et al, 1996). Nestes casos o tratamento endodôntico deve ser realizado somente se o paciente estiver em boas condições clínicas.

$\mathrm{O}$ tratamento odontológico antes e durante a terapia antineoplásica apresenta muitos desafios. A conduta ou protocolo de tratamento odontológico pode requerer modificações decorrentes da oncoterapia e do pouco tempo para instituir o plano de tratamento ideal devido à urgência muitas vezes do início do tratamento oncológico (Brennan, Woo, \& Lockhart, 2008).

Portanto, o principal objetivo do tratamento odontológico no paciente oncológico é adequar o meio bucal buscando eliminar ou estabilizar as condições bucais para minimizar o risco de infecção local e sistêmica, durante e após o tratamento do câncer, e dessa forma melhorar a qualidade de vida do paciente. Sendo assim, o conhecimento adequado do processo de diagnóstico, do estadiamento do tumor e do planejamento da oncoterapia associado a uma adequada avaliação odontológica são necessários para auxiliar o cirurgião-dentista a planejar o tratamento (Brennan, Woo, \& Lockhart, 2008).

Assim, durante a realização do tratamento endodôntico nos pacientes oncológicos, alguns critérios devem ser respeitados para evitar complicações. Dentre eles deve-se evitar a realização de cirurgia periapical, optar pelo tratamento endodôntico convencional evitando sempre que possível extrações e realizar uma boa obturação e selamento coronário (Coelho, Gomes, \& Fernandes, 2010), assim como adequado isolamento absoluto, adaptação do grampo quando possível. O objetivo deste trabalho foi apresentar casos clínicos de pacientes em tratamento oncológico com cirurgia, quimioterapia e/ou radioterapia ou que serão submetidos a transplante de medula óssea, relatando os principais desafios e cuidados durante o tratamento odontológico, dando ênfase aos cuidados durante a realização do tratamento endodôntico.

\section{Metodologia}

Este estudo é de caráter qualitativo e descritivo, e foi realizado por meio de três relatos de casos clínicos de pacientes submetidos a tratamento oncológico no Hospital do Câncer- Hospital de Clínicas de Uberlândia (UFU) e que tiveram necessidade de realização de tratamento endodôntico.

Os dados coletados no trabalho não identificaram os pacientes e todos assinaram e foram orientados em relação ao Termo de Consentimento Livre e Esclarecido (TCLE).

\section{Relato de Caso Clínico 1}

Paciente gênero feminino, 55 anos, histórico de linfoma não Hodgkin de células B do Manto, internada no Hospital do Câncer- Hospital de Clínicas de Uberlândia (UFU) para tratamento quimioterápico (5 ciclos de HyperCVAD - 3 blocos A ciclofosfamida, vincristina e doxorrubicina e 2 B methotrexato e citarabina). Foi solicitado atendimento odontológico devido relato de dor no dente 23 . 
Ao exame clínico intrabucal, foi observado que o dente 23 apresentava-se com cárie extensa, coloração normal, resposta positiva ao teste de sensibilidade frio, ausência de fístula, de edema e de mobilidade.

Ao exame radiográfico periapical verificou-se que o mesmo dente apresentava canal único amplo, sem aparente reabsorção apical (Figura 1). Foram então solicitados exames hematológicos complementares (hemograma e coagulograma TAP - tempo de ativação de protrombina e TTPA - tempo de tromboplastina parcial ativada) antes do início do tratamento endodôntico.

Figura 1. Aspecto radiográfico inicial do dente 23.

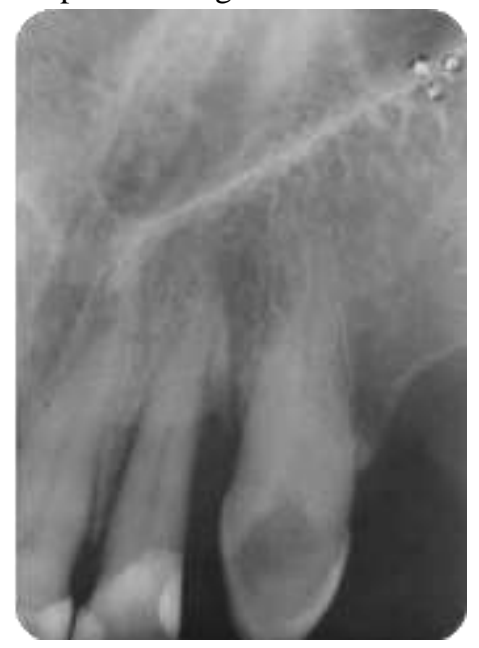

Fonte: Prontuário do paciente.

Diante das características clínicas e radiográficas foi dado o diagnóstico clínico provável de Pulpite Irreversível Sintomática com região periapical normal, e indicação de Tratamento Endodôntico Radical. Foi feita profilaxia antibiótica prévia com 1 grama de amoxicilina 1 hora antes do início do tratamento. Em seguida foi realizada a remoção do tecido cariado com broca esférica 1012 (KG Sorensen, Cotia, São Paulo, Brasil) e término do preparo para acesso a câmara pulpar utilizando broca EndoZ (KG Sorensen, Cotia, São Paulo, Brasil). Sendo todo procedimento feito sob o uso de isolamento absoluto.

A estimativa de odontometria foi feita com auxílio da radiografia inicial e após preparo do terço médio e cervical com brocas Gates Glidden (Dentsply, Petrópolis, Riode Janeiro, Brasil) em 2/3 terços do comprimento estimado aparente.

Após a obtenção da odontometria igual a 22mm com o auxílio do localizador apical RomiApex® (RomiApex, VDW GmbH, München), o preparo do terço apical foi feito utilizando limas Kerr (Dentsply, Petrópolis, Rio de Janeiro, Brasil) pela Técnica Clássica associada a Técnica Escalonada (lima memória número 45).

Durante todo o preparo biomecânico, a irrigação foi feita com hipoclorito de sódio a 1\% (Asfer Industria Química Ltda. São Caetano do Sul, São Paulo, Brasil) por meio da ponta de irrigação NaviTip (Navitips, Ultradent, Salt Lake City, Utah, EUA) $21 \mathrm{~mm}$ e seringa Ultradent ${ }^{\circledR}$ (Ultradent, Salt Lake City, Utah, EUA) e um movimento de ejeção lento e suave.

Ao final da primeira sessão optou-se por colocar a medicação intracanal com pasta de hidróxido de cálcio (Maquira, Maringá, Brasil) associado a soro fisiológico, bolinha de algodão estéril e selamento provisório com cimento de ionômero de vidro Maxxion R® (Joinville, Santa Catarina, Brasil).

Na sessão seguinte após o intervalo de um mês entre as sessões devido à internação para tratamento oncológico foi feita antibioticoterapia profilática após a avaliação dos exames hematológicos complementares da paciente o tratamento endodôntico foi finalizado. Foi feita radiografia de prova do cone (Figura 2) de acordo com a lima memória, utilizando cones de guta-percha FM (Dentsply, Petrópolis, Rio de Janeiro, Brasil) calibrados na régua calibradora Prisma® (Prisma Instrumentos Odontológicos, 
Pirituba, São Paulo, Brasil) após desinfecção em solução de hipoclorito de sódio a 1\% (Asfer Industria Química Ltda. São Caetano do Sul, São Paulo, Brasil) durante 1 minuto.

Figura 2. Radiografia da prova do cone.

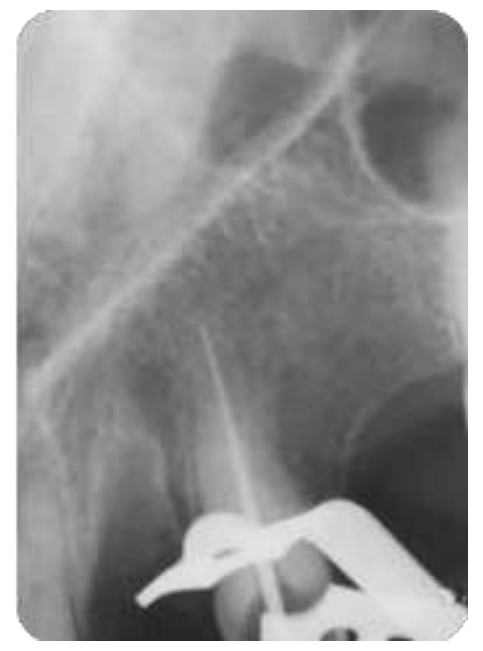

Fonte: Prontuário do paciente.

A obturação foi feita utilizando cimento endodôntico a base de resina e hidróxido de cálcio Sealer 26 (Dentsply, Petrópolis, Rio de Janeiro, Brasil) e a Técnica de Condensação Lateral e em seguida foi realizada radiografia final para confirmar a completa obturação dos canais radiculares.

Figura 3. Radiografia final.

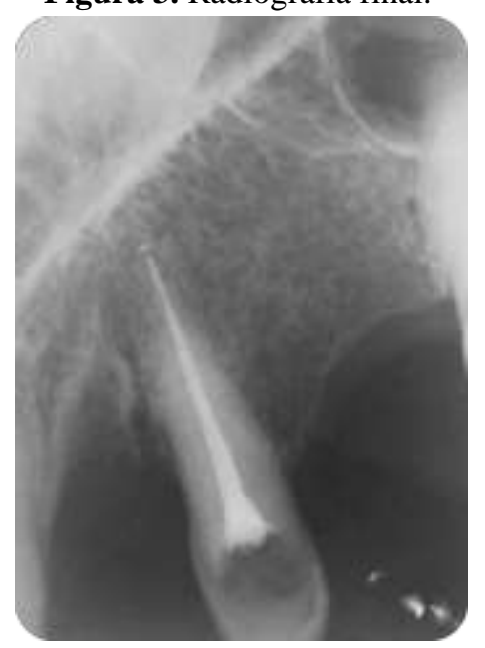

Fonte: Prontuário do paciente.

$\mathrm{Na}$ consulta de acompanhamento, a paciente encontrava-se com ausência de sinais e sintomas de doença no dente $23 \mathrm{e}$ após orientações a paciente recebeu alta provisória para realizar o transplante de medula óssea. Foi realizada posterior restauração em resina composta.

\section{Relato de Caso Clínico 2}

Paciente gênero masculino, 77 anos, histórico de carcinoma epidermóide moderadamente diferenciado em região de amígdala D, estadiamento T3N1M0 realizou 39 sessões de radioterapia, utilizando cobaltoterapia, com dose total de 7020 cGy 
e quimioterapia (Cisplatina). Relata hipertensão arterial sistólica e refluxo gastro esofágico em uso de atenolol e omeprazol. Foi encaminhado para atendimento odontológico com necessidade de tratamentoendodôntico no dente 33.

Ao exame clínico intrabucal, foi observado que o dente 33 apresentava-se com cárie extensa, devido à cárie relacionada à radiação, coloração escurecida, resposta negativa ao teste de sensibilidade térmico frio, presença de mobilidade, ausência de fístula e de edema.

Ao exame radiográfico periapical verificou-se que o mesmo dente apresentava canal único amplo e imagem radiográfica indicando lesão radiolúcida na região periapical do dente 33 (Figura 4).

Figura 4. Aspecto radiográfico inicial do dente 33.

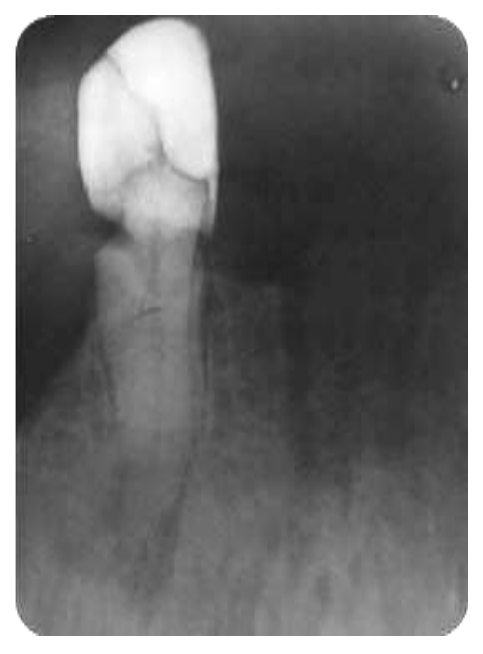

Fonte: Prontuário do paciente.

Diante das características clínicas e radiográficas foi dado o diagnóstico clínico provável de Periodontite Apical Crônica Reabsortiva, com indicação de Tratamento Endodôntico Radical. Foi prescrito previamente 1 grama de amoxicilina 1 hora antes do procedimento realizado, foi feita remoção do tecido cariado com broca esférica 1012 (KG Sorensen, Cotia, São Paulo, Brasil) e término do preparo para acesso a câmara pulpar utilizando broca EndoZ (KG Sorensen, Cotia, São Paulo, Brasil). Sendo todo procedimento feito sob isolamento absoluto.

A estimativa de odontometria e o preparo dos terços cervical e médio foi feito da mesma forma que no caso clínico 1. O comprimento real de trabalho foi definido em $23 \mathrm{~mm}$ e a lima memória utilizada foi a lima tipo Kerr (Dentsply, Petrópolis, Rio de Janeiro, Brasil) número 55 (Figura 5).

Figura 5. Radiografia de odontometria.

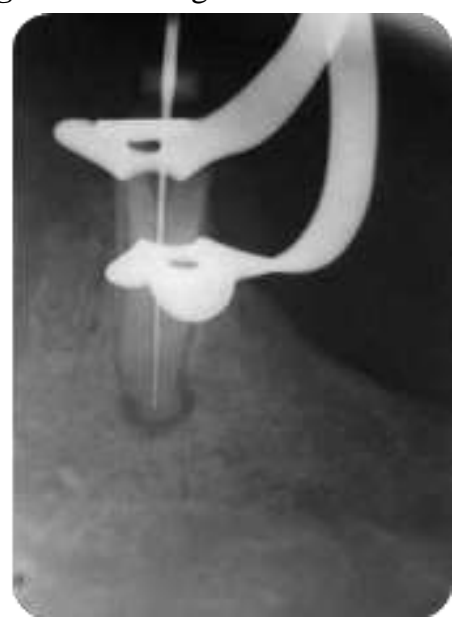

Fonte: Prontuário do paciente. 
O preparo apical, a medicação intracanal e a obturação seguiram as mesmas técnicas e produtos do caso clínico 1 (Figura 6A e 6B).

Figura 6. A) Radiografia da prova do cone; B) Radiografia final.

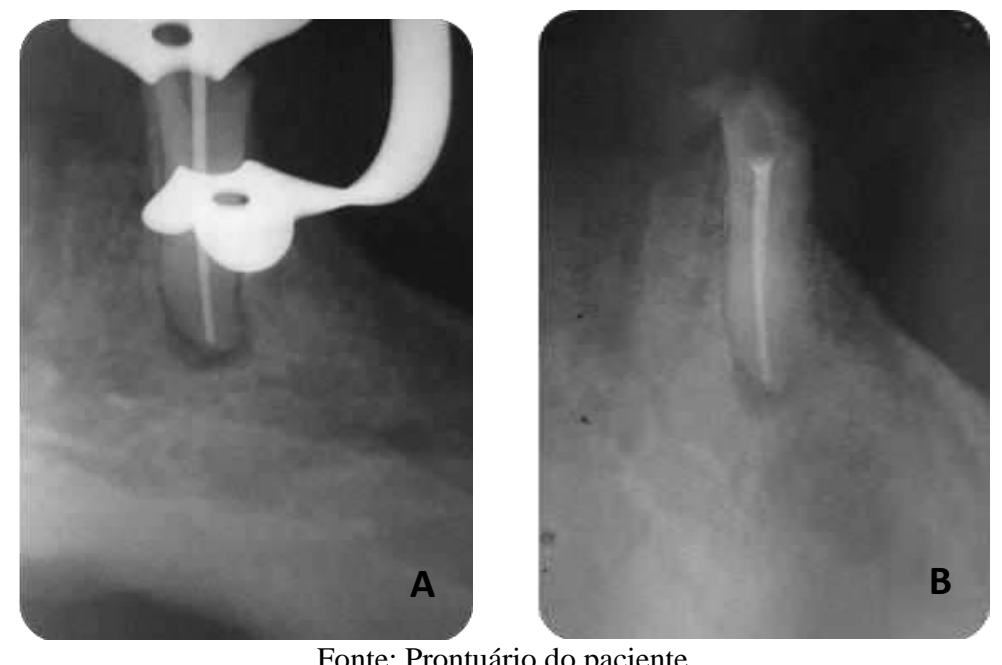

Na consulta de acompanhamento, o paciente estava com ausência de sinais e sintomas de doença no dente 33 e o mesmo segue em proservação. Paciente foi encaminhado para realizar tratamento reabilitador no dente com pino intraradicular de fibra de vidro e restauração em resina composta.

\section{Relato de Caso Clínico 3}

Paciente gênero feminino, 65 anos de idade, com diagnóstico de carcinoma ductal invasivo grau II, estadiamento T2N1Mx pós cirurgia (mastectomia total direita) e tratamento antineoplásico intravenoso (Doxorrubicina + Ciclofosfamida + Paclitaxel + Trastuzumabe) com término no ano de 2014. Atualmente em tratamento antineoplásico oral (Exemestano), e início de osteopenia com possibilidade de uso de bisfosfonato intravenoso (zolendronato) foi encaminhada ao ambulatório de odontologia do Hospital do Câncer de Uberlândia para avaliação do dente 14.

Ao exame clínico intrabucal, foi observado que o dente 14 apresentava-se com cárie extensa, coloração escurecida, resposta negativa ao teste de sensibilidade térmico frio, ausência de mobilidade, presença de fístula e edema.

Ao exame radiográfico periapical para rastreamento da fístula verificou-se que o dente apresentava dois canais com tratamento endodôntico prévio, núcleo metálico fundido e o rastreamento da fístula utilizando cone de guta-percha confirmou necessidade de retratamento do dente 14 (Figura 7).

Figura 7. Radiografia de rastreamento de fístula.

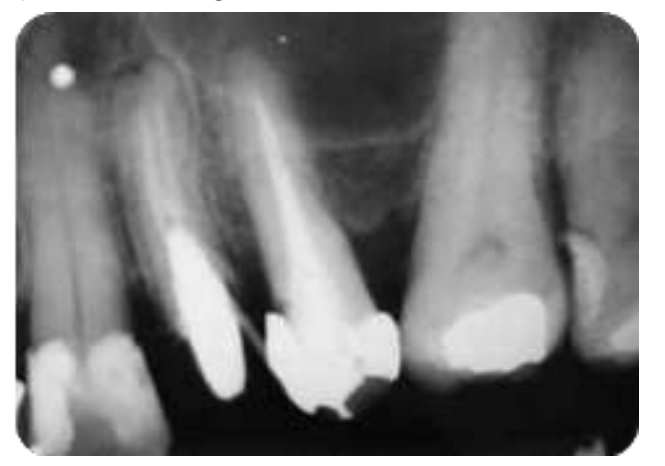

Fonte: Prontuário do paciente. 
Diante das características clínicas e radiográficas foi dado o diagnóstico clínico provável de Abscesso periapical crônico com indicação de Retratamento Endodôntico. Inicialmente o retratamento, foi feita remoção do tecido cariado com broca esférica 1012 (KG Sorensen, Cotia, São Paulo, Brasil), remoção do núcleo metálico fundido (figura 8) com ultrassom profi class® (Dabi Atlante, Ribeirão Preto, São Paulo) e ponta ultrassônica E2D (Helse, Brasil).

Figura 8. Núcleo metálico fundido removido.

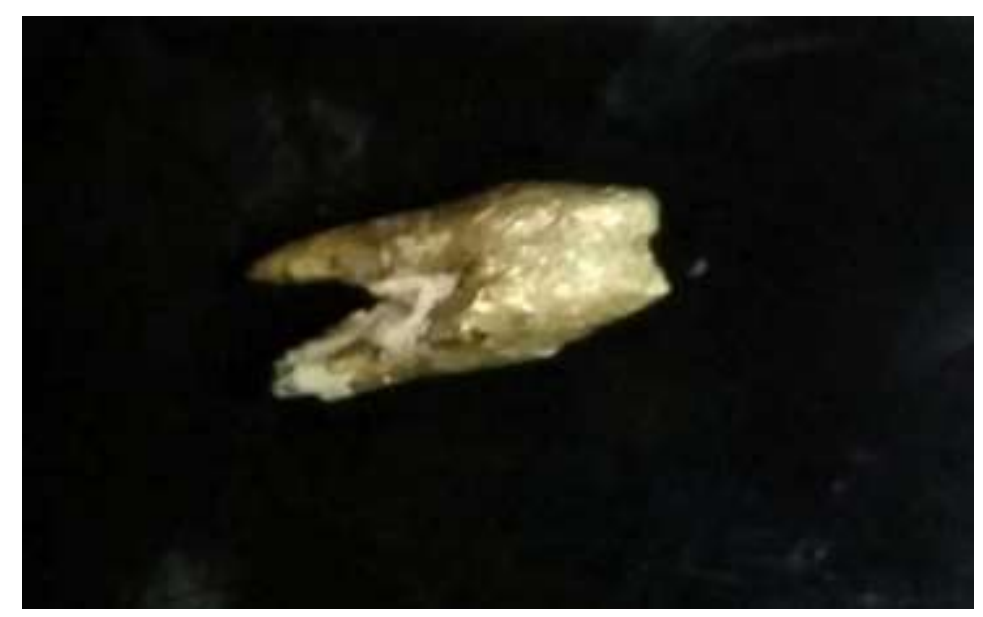

Fonte: Prontuário do paciente.

A estimativa de odontometria foi feita com auxílio da radiografia inicial e após preparo do terço médio e cervical com brocas Gattes Glidden® (Dentsply, Petrópolis, Rio de Janeiro, Brasil) em 2/3 terços do comprimento estimado e todo procedimentofoi feito sob isolamento absoluto (Figura 9).

Figura 9. Isolamento absoluto da região do dente 14.

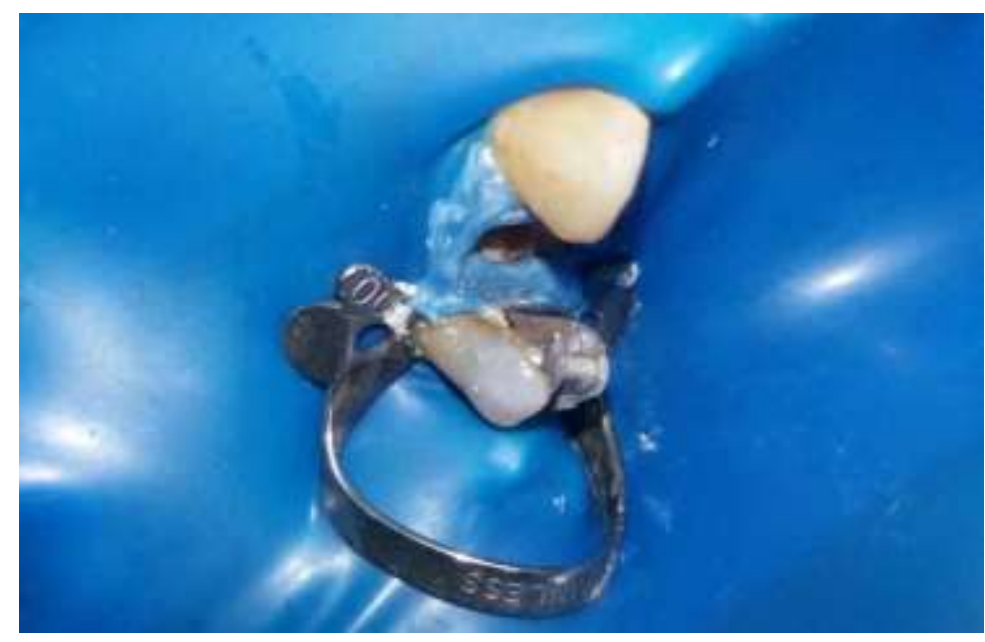

Fonte: Prontuário do paciente.

A estimativa de odontometria e o preparo dos terços cervical e médio foi feito da mesma forma que no caso clínico 1. O comprimento real de trabalho foi definido para o canal vestibular (CV) em $18 \mathrm{~mm}$ e para o canal palatino $(\mathrm{CP})$ em $17,5 \mathrm{~mm}$ e as limas memórias utilizadas foram as limas tipo Kerr (Dentsply, Petrópolis, Rio de Janeiro, Brasil) número 40 para o CP e 45 para o CV. 
Figura 10. Aspecto intraoral após a remoção do núcleo metálico fundido e selamento provisório.

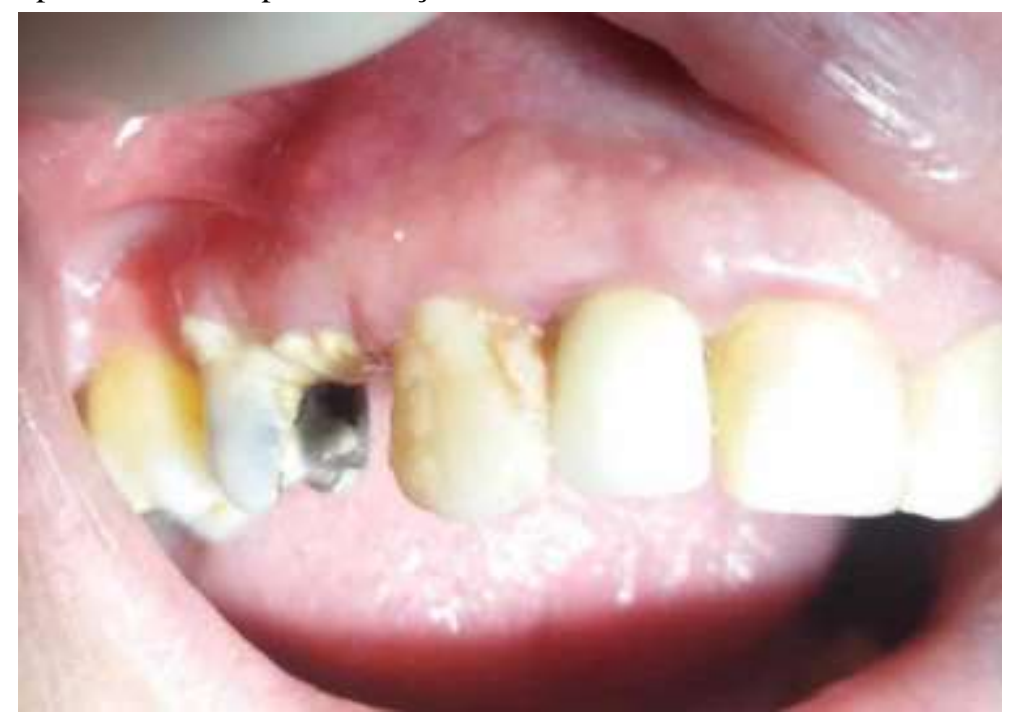

Fonte: Prontuário do paciente.

Na sessão seguinte (após 7 dias) a paciente retornou e deu continuidade ao tratamento endodôntico. Foi realizada nova troca de medicação intracanal com pasta de hidróxido de cálcio (Maquira) associado ao Paramonoclorofenol canforado (Maquira).

Após 15 dias de medicação intracanal e regressão dos sinais e sintomas do dente 14, foi feita radiografia de prova do cone (Figura 11) de acordo com a lima memória, os cones de guta-percha utilizados foram FM (Dentsply) calibrados na régua calibradora Prisma (Prisma Instrumentos Odontológicos) desinfetados em solução de hipoclorito de sódio a 1\% (Asfer Industria Química Ltda) durante 1 minuto.

Figura 11. Radiografia da prova do cone.

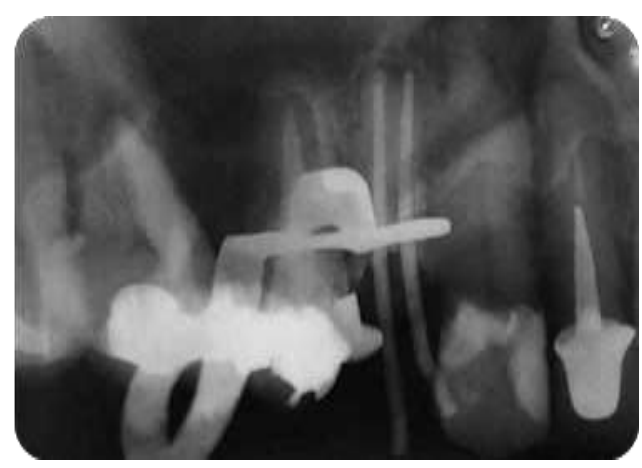

Fonte: Prontuário do paciente.

A obturação seguiu a mesma técnica e produto do caso clínico 1 (Figura 12A e 12B) 


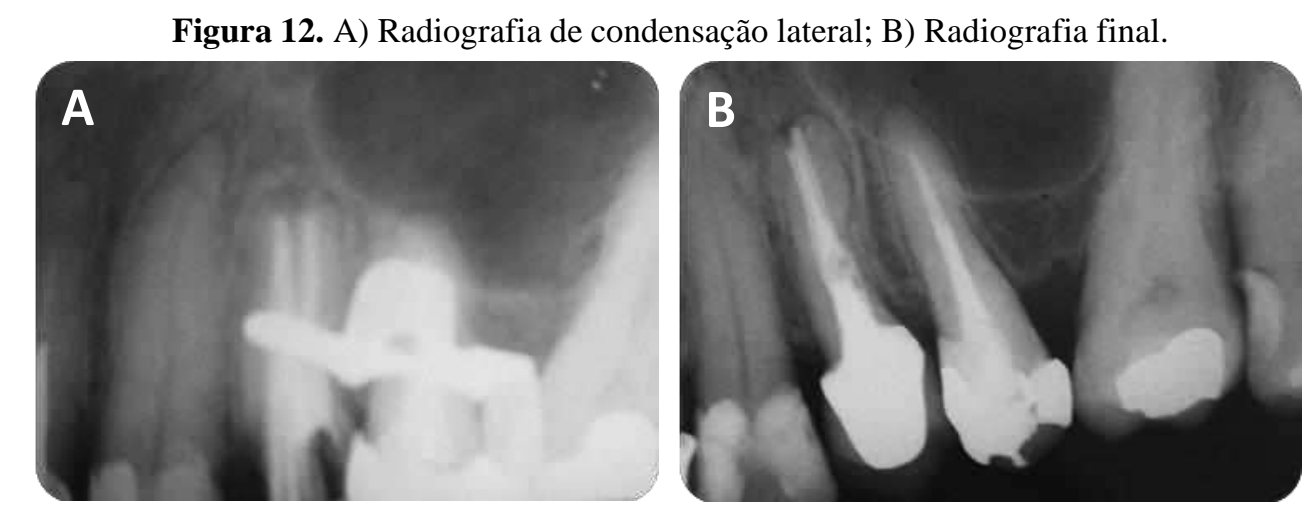

Fonte: Prontuário do paciente.

Na consulta de acompanhamento, o paciente estava com ausência de sinais e sintomas e sem alterações no dente 14 . Paciente encaminhado para reabilitação com núcleo metálico fundido e coroa metalocerâmica.

\section{Discussão}

É de suma importância que os cirurgiões-dentistas e os oncologistas clínicos tenham consciência de que os pacientes com câncer necessitam de cuidado oral específico (Carl W. 1995). O cirurgião-dentista deve acompanhar o paciente em intervalos regulares para avaliar a cavidade oral, prevenindo infecções secundárias (Lunn R. 1998), como também acompanhar o possível surgimento de sequelas resultantes do tratamento oncológico (Lima, Joshi, 2010; Vieira Leite Melo \& Figueiredo 2012).

O ideal para o paciente oncológico é que estes passem por avaliação odontológica pelo cirurgião dentista tão logo tenham sua doença diagnosticada, para que desta forma o tratamento odontológico anteceda o oncológico (Andrews N. \& Griffiths 2001). Para isto, uma abordagem multidisciplinar se faz necessária com envolvimento de toda a equipe desde o início do tratamento (Andrews \& Griffiths 2001). Porém nem sempre é possível que o tratamento odontológico anteceda o início do tratamento oncológico, como no caso 3 do presente trabalho.

As principais doenças classificadas como onco-hematológicas são: os linfomas, as doenças mieloproliferativas, o mieloma múltiplo, as leucemias, e trombocitopenia imune primária, a hemoglobinúria paroxística noturna e a síndrome mielodisplásica (Gonçalves 2015).O linfoma se desenvolve nos gânglios linfáticos e uma possível abordagem terapêuticapara esta neoplasia maligna é o transplante de medula óssea. Como foi no caso 1 apresentado no presente trabalho o qual a paciente passou por avaliação odontológica prévia ao transplante. Os linfomas podem ser classificados em linfomas Hodgkin e não Hodgkin. O linfoma não Hodgkin é considerado um tipo mais comum, não possui um tipo celular característico (célula de Reed Sternberg), apresenta expressiva heterogeneidade morfológica, imunofenotípica e genética (Costa, Souza, Pinto Júnior, Abreu, Gomez \& Silva 2014)

Em condições de imunossupressão todo foco infeccioso pode ser ativado, e desta forma toda infecção em pacientes prétransplantes de células hematopoiéticas devem ser erradicadas previamente (Fishman. 2007). O tratamento endodôntico nestas condições visa à manutenção do elemento dental e a redução do risco de infecção decorrente do tratamento odontológico nestes pacientes, porém é muito importante que o paciente também seja orientado com relação aos cuidados com a saúde bucal.

Na medicina, os exames laboratoriais representam importância em grande parte das decisões de diagnósticos e tratamentos médicos (Netto, Andriolo, Fraige Filho, Tambascia, Gomes, \& Melo 2009). Porém para o cirurgião dentista é importante salientar que uma "bateria" de exames complementares para os pacientes, não deve ser rotina, pois alguns exames devem ser solicitados aos pacientes que realmente tem a indicação de acordo com o histórico e exame físico (Mathias, Guarantini, Gozzani, \& Rivetti 2006). Não é suficiente observar os valores obtidos e compará-los com os valores de referência apresentados 
nos exames. O fundamental é ter conhecimento para identificar o que significa cada alteração encontrada ou que medidas préoperatórias terão de ser realizadas (Netto, Andriolo, Fraige Filho, Tambascia, Gomes, \& Melo 2009).

O hemograma é uma das principais ferramentas para a avaliação de diversas situações, o resultado anormal pode ser considerado uma contra-indicação momentânea ou definitiva para a execução de alguns procedimentos odontológicos invasivos. Outro exame importante é a solicitação do coagulograma, como TAP e TTPA que poderá detectar alterações da hemostasia (Amaral, Nascimento, Pereira, Parizi, Straioto, \& Amaral 2014).

O carcinoma espinocelular (CEC) também conhecido como carcinoma epidermóide e carcinoma de células escamosas, diagnóstico encontrado no paciente do caso 2 do presente trabalho representa aproximadamente $90 \%$ a $95 \%$ das neoplasias malignas da cavidade oral. Caracteriza pela agressividade e alta incidência de metástase (Lira, Godoy, \& Gomes, 2014). A radioterapia tem sido largamente utilizada para o tratamento dos tumores de cabeça e pescoço, de forma exclusiva, pós tratamento cirúrgico ou concomitante à quimioterapia. Ela promove a ionização no meio onde incide, tornando-o eletricamente instável (radiação ionizante). Esse tipo de radiação age no DNA nuclear, e leva a célula a perda da sua capacidade reprodutiva ou a sua morte celular (Jham \& Freire 2006).

A radioterapia é capaz de promover várias alterações (químicas, físicas ebiológicas) ao nível celular, por efeito direto e também por obliteração da microcirculação local, como se pode observar na osteorradionecrose (Rolim, Costa, \& Ramalho 2011) que é um dos mais graves efeitos colaterais na região de cabeça e pescoço irradiada. O local de maior acometimento é a mandíbula. Nesta complicação as células ósseas e a vascularização podem ser irreversivelmente injuriadas (Rolim, Costa, \& Ramalho 2011). Sua ocorrência está relacionada a vários fatores como a qualidade e quantidade de radiação, fracionamento da dose, localização da lesão, qualidade periodontal, dental e óssea, e também do grau de trauma sobre os tecidos (Cacelli \& Rapoport 2008). Por isso deve-se sempre que possível preservar o dente na cavidade bucal para não correr risco do desenvolvimento da osteorradionecrose.

Caso a cárie relacionada à radiação tenha comprometido toda a coroa dentária e também comprometido a polpa dental, o tratamento endodôntico deve ser realizado com consequente obliteração do conduto, sob o uso de antibioticoterapia profilática, deixando a raiz "sepultada" no alvéolo (Vissink, Jansma, Spijkervet, Burlage, \& Coppes 2003). Na polpa dental, a radiação causa alterações significativas o que predispõe a infecções. A camada odontoblástica passa a demonstrar maior fragilidade e atrofia. Há também a redução dos elementos vasculares em conjunto com a fibrose. Dessa forma a resposta pulpar à infecção, traumas e procedimentos dentários diversos é consequentemente, comprometida (Silverman \& Chierci, 1965).

Durante o tratamento endodôntico a determinação do limite de instrumentação deve ser realizada de forma precisa e sem penetração de materiais nos tecidos periapicais. Antes do estabelecimento do correto comprimento de trabalho com a finalidade de prevenir que substâncias químicas promovam irritação na região periapical deve ser evitado o uso de soluções irrigadoras cáusticas (Cox 1976). A técnica de instrumentação escalonada nestes casos tem se mostrado mais efetivas na remoção de debris dentinários na realização destes tratamentos endodônticos (Rodrigues, Franzi, \& Dedivitis 2006).

Nos pacientes que não passaram por radioterapia há duas opções de tratamento em dentes com cáries que resultaram em pulpite irreversível ou necrose pulpar: tratamento endodôntico ou exodontia. Entretanto em pacientes irradiados, a exodontia está relacionada à alta taxa de incidência de desenvolvimento de osteorradionecrose (Stevenson-Moore \& Epstein 1993). Desta forma, a exodontia nestes pacientes é usualmente reduzida aos dentes patologicamente envolvidos e não apresentam condições de serem mantidos. A opção preferível para dentes restauráveis ou que serão sepultados é o tratamento endodôntico (Santos, Noro-Filho, Caputo, Souza, Andrade, \& Giovani 2013). Visando isto, que foi realizado tratamento endodôntico em um dos pacientes relatado com a finalidade de eliminar o foco de infecção e auxiliar na manutenção do dente.

De acordo com dados do Instituto Nacional do Câncer (INCA), o tipo de câncer mais comum entre as mulheres é o câncer de mama depois do câncer de pele não melanoma. No tratamento adjuvante e paliativo de pacientes pós-menopausa com 
câncer de mama com receptores hormonais positivos, tem se utilizado inibidores da aromatase, considerado um modulador seletivo dos receptores de estrógeno. Essas drogas agem bloqueando a atividade da aromatase, e desta forma torna os níveis circulantes de estrógenos praticamente indetectáveis. Estudos apontam que a presença do estrógeno tem uma evidente atividade protetora sobre os ossos, mas o mecanismo exato não é claro (Cassol \& Garicochea 2005).

O método mais amplamente empregado para o diagnóstico e monitorização da osteoporose é a densitometria óssea (Lester, Dodwell, McCloskey, \& Coleman 2005). A osteopenia é definida como uma densidade óssea entre 1 e 2,5 e desviopadrão abaixo desse pico (Kanis 1994). Os bisfosfonatos são medicamentos administrados a pacientes portadores de metástases ósseas e para pacientes com osteoporose (Gegler, Cherubini, Figueiredo, Yurgel, \& Azambuja 2006).

A osteonecrose avascular, induzida por medicamentos, é uma necrose dos maxilares e tem sido associada a uso de bisfosfonatos (Gegler, Cherubini, Figueiredo, Yurgel, \& Azambuja 2006). Estudos têm demonstrado a associação do uso crônico de bisfosfonatos com a osteonecrose em pacientes que foram submetidos à exodontias ou cirurgias envolvendo tecidos ósseos na maxila ou mandíbula (Ruggiero, Mehrotra, Rosenberg, \& Engroff, 2004). A ocorrência da osteonecrose nos ossos da arcada dentária está associado ao fato dessas estruturas se encontrarem em contato direto com a flora da cavidade bucal o que favorece assim, a instalação de quadros infecciosos, e quando instalada a infecção é algo de difícil controle tanto pelas alterações do metabolismo ósseo causadas pelos bisfosfonatos, quanto pela baixa imunidade do paciente (Gegler, Cherubini, Figueiredo, Yurgel, \& Azambuja 2006).

Como atualmente os bisfosfonatos são drogas amplamente utilizadas, como no paciente do caso 3 do presente trabalho o cirurgião-dentista deve estar atento para os efeitos que esta medicação pode causar no paciente, como os procedimentos e o prognóstico do tratamento odontológico podem afetar o tratamento oncológico (Sampaio, Veloso, \& Barbosa 2010). Considerando o processo de reparo de uma periodontite apical quatro fases são importantes: injúria, inflamação, proliferação e remodelação (Estrela 2009). Devido à medicação interferir no processo de remodelação óssea e também agir inibindo mediadores da inflamação, os bisfosfonatos podem influenciar no processo de reparo de lesões ósseas. Sendo assim também podem interferir no prognóstico do tratamento endodôntico (Aguirre, Altman, Vanegas, Franz, Bassit, \& Wronski 2010).

O processo patobiológico envolvido na osteonecrose associada ao uso de bisfosfonatos ainda não é totalmente compreendida, mas parece que a supressão profunda dos osteoclastos tem um papel fundamental, associada com o efeito tóxico dos bisfosfonatos nos tecidos moles, incluindo a anti-angiogênese (Reid 2009). Apesar de que as lesões ósseas possam ocorrer espontaneamente, fatores predisponentes como trauma protético ou cirúrgico contribuem para o desenvolvimento da osteonecrose nestes pacientes em uso de bisfosfonatos. A extração dental é por exemplo, um fator precipitante comumente observado (Ruggiero, Mehrotra, Rosenberg, \& Engroff, 2004).

Há muitas variáveis que podem interferir no tratamento endodôntico dos pacientes em uso de bisfosfonatos, principalmente os por via intravenosa. No tratamento em oncologia, a condição imunológica comprometida dos pacientes, os tratamentos concomitantes a que estes são submetidos e os próprios efeitos do câncer podem estar associados à dificuldade ou impossibilidade do organismo em reparar as lesões periapicais (Sampaio, Veloso, \& Barbosa 2010). Porém quando há necessidade de intervenção, o tratamento endodôntico é preferível a cirurgias, pois há maior capacidade do organismo em manter a infecção restrita ao local, ou seja, ao sistema de canais radiculares (Estilo, Van Poznak, Williams, Bohle, \& Lwin 2008).

Esses fatores reforçam a importância do conhecimento do cirurgião-dentista sobre estas patologias e como as formas de tratamento podem afetar diretamente o plano de tratamento odontológico.

\section{Conclusão}

A integração do cirurgião-dentista com a equipe oncológica na atenção e cuidado do paciente em tratamento oncológico é extremamente importante em todos os estágios da doença. Um adequado plano de tratamento prévio ao início da terapia 
antineoplásica é a melhor opção para evitar complicações futuras. Porém como muitas vezes o tempo entre o diagnóstico e início do tratamento é curto, o cirurgião dentista deve estar apto a realizar a melhor forma de tratamento possível a fim de reduzir danos decorrentes do tratamento.

Os principais cuidados do tratamento endodôntico no paciente oncológico devem ser:

- Deve apresentar o maior grau de precisão possível durante todas as etapas que o envolvam desde o diagnóstico até o término do tratamento endodôntico, com uma adequada obturação dos canais radiculares, sem que ultrapasse o comprimento real de trabalho, preservando assim, o dente na cavidade bucal e reduzindo os focos de infecção;

- Acompanhar o paciente em intervalos regulares;

- Tratamento odontológico antes do oncológico;

- Realizar exames complementares (hemograma, coagulograma) antes de iniciar o tratamento odontológico;

- Uso de antibioticoterapia profilática antes do tratamento odontológico invasivo;

- Em pacientes irradiados, deve-se manter o dente do paciente para evitar o risco de osteorradionecrose. Por isso em dentes com cárie relacionada à radiação e destruição total da coroa, indica-se a realização do tratamento endodôntico e o sepultamento da raiz;

- Tratamento endodôntico é o tratamento de primeira escolha em pacientes que fazem uso de bisfosfonatos. Essa medicação interfere no processo de remodelação óssea e pode causar osteonecrose após cirurgias e podem dificultar o reparo de lesões periapicais;

Portanto, é de fundamental importância que o tratamento odontológico sempre que possível não interfira no tratamento oncológico do paciente e tenha por finalidade minimizar complicações e melhorar a qualidade de vida dos pacientes.

\section{Referências}

Aguirre J. I., Altman M. K., Vanegas S. M., Franz S. E., Bassit A. C., \& Wronski T. J. (2010). Effects of alendronate on bone healing aftes tooth extraction in rats. Oral dis. Houndmills. (7):674-85.

Albuquerque R. A., Morais V. L. L., \& Sobral A. P. V. (2007). Protocolo de atendimento odontológico a pacientes oncológicos pediátricos - revisão da literatura. Revista de odontologia da UNESP. 36(3): 275-280.

Amaral C. O. F., Nascimento F. M., Pereira F. D., Parizi A. G., Straioto F. G., \& Amaral M. S. P. (2014). Bases para interpretação de exames laboratoriais na prática odontológica. UNOPAR Cient Ciênc Biol Saúde. 16(3):229-37.

Andrews N., \& Griffiths C. (2001). Dental complications of head and neck radiotherapy: Part 2. Aust Dent J. 46:174-82.

Antônio A. M., Mais F., \& Dias R., (2001). Reações adversas da radioterapia: cuidados pré, trans e pós-operatório. Rev Odontol. 9(19): 12-9.

Bartl R. F. B., Von Tresckow E., \& Bartl C. (2007). Bisphosphonates in Medical Pratice: Actions Side Effects, Indications, Strategies. 1st ed. ed. Berlin (Germany): Springer.

Brennan M. T., Woo S-B., \& Lockhart P. B. (2008). Dental treatment planning and management im the patient who has cancer. Dent Clin N Am. 52:19-37.

Cacelli E. M. N., Rapoport A. (2008). Para-efeitos das irradiações nas neoplasias de baco e orofaringe. Ver Bras Clr Cabeça Pescoço, 3(4):198-201.

Carl W. (1995). Oral complications of local and systemic cancer treatment. Curr. Opin. Oncol., Hagerstown. 7(4):320-324.

Cassol L. B., \& Garicochea B. (2005). Uso de inibidores da aromatase no tratamento de câncer de mama e osteoporose. Scientia Medica, PUCRS. 15(4).

Coelho A. L., Gomes O. S., \& Fernandes M. H. (2010). Osteonecrose dos maxilares associada ao uso de bisfosfonatos. Parte II: Linhas de orientação na consulta de medicina dentária. Revista Portuguesa de Estomatologia, Medicina Dentária e Cirurgia Maxilofacial. 52(3): 185-200.

Costa J. L. B. M., Souza N. C., Pinto Júnior A. A. C., Abreu M. H. N. G., Gomez R. S., \& Silva M. Ê. S. (2014). Tratamento odontológico prévio a transplante de células tronco-hematopoiéticas: um relato de caso. Arq Odontol, 50(1): 20-27.

Cox F. L. (1976). Endodontics and the irradiated patient. Oral Surg Oral Med Oral Pathol. 42(5):679-684. 
De Castro R. M., Dezotti M., Azevedo L., Aquilante A., \& Xavier C. R. (2002). Ver Odontol UNICID. 14(1):63-74.

Estilo C. L., Van Poznak C. H., Williams T., Bohle G. C., Lwin P. T., et al. (2008). Osteonecrosis of maxila and mandible in patients with advanced cancer treated with bisphosphonates therapy. Oncolosgist, Dayton. (8):911-20

Estrela C. (2009). Endodontic Science. São Paulo - SP: Artes Médicas. 1140p.

Fishman J. A. (2007). Infection in solid-organ transplan recipientes. N Engl J Med. 357:2601-14.

Gegler A., Cherubini K., Figueiredo M. A., Yurgel L. S., \& Azambuja A. A. (2006). Bisfosfonatos e osteonecrose maxilar: revisão da literatura e relato de dois casos. Revista Brasileira de Cancerologia. 52(1): 25-3.

Gonçalves C. F. (2015). Acompanhamento odontológico conservador em pacientes sob tratamento onco-hematológico. Tese (Doutora em Ciências da Saúde) Programa de pós graduação Universidade de Brasília - DF. 74f.

Guerra M. R., Galio C. V. M., \& Mendonça G. A. (2005). Risco de câncer no Brasil: tendências e estudos epidemiológicos mais recentes. Revista Brasileira de Cancerologia, 51(3):227-234.

Jereczek-Fossa B. A., \& Orecchia R. (2002). Radiotherapy-induced mandibular bone complications. Cancer Treat Ver. 28:65-74.

Jham B. C., \& Freire A. R. S. (2006). Complicações bucais da radioterapia em cabeça e pescoço. Reb Bras Otorrinolaringol, Belo Horizonte - MG. 72 (5):704708 .

Joshi V. K. (2010). Dental treatment planning and management for the mouth cancer patient. Oral Oncol. 46:475-92.

Katansas. A. N., Rogers S. N., \& Martin M. V. (2002). A pratical guide for patients undergoing exodontia following radiotherapy to the oral cavity. Dent Update. 29:498-503

Lester J., Dodwell D., McCloskey E., \& Coleman R. (2005). The causes and treatment of bone loss associated with carcinoma of the breast. Cancer Treat Rev. $31: 115-42$.

Lima E. N. A. (2010). Avaliação de alterações orais em pacientes submetidos a transplante de medula óssea. Dissertação de mestrado em patologia oral, Universidade Federal do Rio Grande do Norte, Natal.

Lira A. A., Godoy G. P., Gomes D. Q. C., et al. (2009). Carcinoma de células escamosas indiferenciado em paciente jovem: relato de caso. Int J Dent. 8:172-6. Lunn R. (1998). Oral mangement of the cancer patient. Part II: chemotherapy. Probe, Adelaide. 32(2):58-65.

Mathias L. A. S. T., Guarantini A. A., Gozzani J. L., \& Riventti L. A. (2006). Exames complementares pré-operatórios: análise crítica. Ver Brás Anestesiol. 56 (6):658-68.

Netto A. P., Andriolo A., Fraige Filho F., Tambascia M., Gomes M. B., Melo M., et al. (2009). Atualização sobre hemoglobina glicada (HbA10) para avaliação do controle glicêmico e para o diagnóstico do diabetes: aspectos clínicos e laboratoriais. J Brás Patol Med Lab. 45(1):31-47.

Paiva M. D. E. B., Biase R. C. C. G., Moraes J. C. C., Ângelo A. R., \& Honorato M. C. T. M. (2010). Complicações orais decorrentes da terapia antineoplásica. Arquivos de odontologia. 4(1): 48-55.

Reid I. R. (2009). Osteonecrosis of the jaw: who gets it, and why? Bone. 44:4-10.

Rodrigues H. M., Franzi E. A., \& Dedivitis R. A. (2006). A radioterapia e suas implicações nos tratamentos endodônticos. Rev. Bras. Cir. Cabeça Pescoço. 35 (1):57-60.

Rolim A. E. H., Costa L. J., \& Ramalho L. M. P. (2011). Repercussões da radioterapia na região orofacial e seu tratamento. Radiol Bras. 44 (6):388-395.

Ruggiero S. L. (2009). Bisphosphonates-related osteonecrosis of the jaw (BRONJ): initial discovery and subsequent development. J Oral Maxillofac Surg. 67(5 Suppl):13-18.

Ruggiero S. L., Mehrotra B., Rosenberg T. J., \& Engroff S. L. (2004). Osteonecrosis of the jaws associated with the use of biphosphonates: a review of 63 cases. J Oral Maxillofac Surg. 62:527-534.

Sampaio F. C., Veloso H. H., \& Barbosa D. N. (2010). Mecanismos de ação dos bisfosfonatos e sua influência no prognóstico do tratamento endodôntico. Rev. Fac. Odontol. Porto Alegre. 51(1):31-38.

Santos C. C., Noro-Filho G. A., Caputo B. V., Souza R. C., Andrade D. M. R., \& Giovani E. M. (2013). Condutas e práticas efetivas e recomendadas ao cirurgião dentista no tratamento pré, trans e pós do câncer bucal. J Health Sci Inst. 31(4):368-72.

Santos D. B. A., Lattaro R. C. C., \& Almeida D. A. (2011). Cuidados paliativos de enfermagem ao paciente oncológico terminal: Revisão de literatura. Revista de Iniciação Científica da Libertas. São Sebastião do Paraíso. 1(1): 72-84.

Santos P. S. S., \& Magalhães M. H. C. G. (2006). Avaliação da mucosite oral em pacientes que receberam adequação bucal prévia ao transplante de medula óssea. Revista da Pós-Graduação da FOUSP. 13(1).

Sena C., Souza F., Morais L., Pinto L., \& Melo N. (2001). Protocolo de conduta para tratamento de pacientes portadores de câncer bucal que realizarão radioterapia. FOA. 3(1):62-6. .)

Silva B. A. C., Silva P., \& Faria A. M. C. (1996). Pacientes de alto risco em odontologia. (2a ed.), Revinter. Cap. 19, p. 53-55. 
Research, Society and Development, v. 10, n. 11, e446101119789, 2021

(CC BY 4.0) | ISSN 2525-3409 | DOI: http://dx.doi.org/10.33448/rsd-v10i11.19789

Silverman S., \& Chierci G. (1965). Radiation therapy of oral carcinomal. Efects on oral tissues and management of the periodontum. J Periodontol. 36:478-484.

Silverman S., Eversole L. R., \& Truelove E. L. (2002) Fundamentos de medicina oral. Guanabara Koogan, Cap. 10, p. 53-55.

Stevenson-Moore P., \& Epstein J. B. (1993). The management of teeth in irradiated sites. Oral Oncol Eur J Cancer. 29B:39-43.

Vieira D. L., Leite A. F., Melo N. S., \& Figueiredo P. T. S. (2012). Tratamento odontológico em paciente oncológico. Oral Sci. 4(2):37-42.

Vissink A., Jansma J., Spijkervet F. K., Burlage F. R., \& Coppes R. P. (2003). Oral sequele of head and neck radiotherapy. Crit. Rev Oral boil Med. 14(3):199212.

Who Study Group. (1994). Assessment of fracture risk and its applications to screening for postmenopausal osteoporosis. World Health Organ Tech Rep Ser. 843:1-129.

Yamaguchi N. H. (2002). O câncer na visão da oncologia. In M. M. Carvalho (Org.), Introdução à psiconcologia. Campinas, SP. 